\title{
Prevalence of Cerebrospinal Fluid Leak in Traumatic Head Injury at a Tertiary Care Center
}

\author{
Muhammad Junaid', Asad Nabi², Muhammad Aslam Khan ${ }^{3}$, Muhammad Umair ${ }^{4}$ \\ ${ }^{1}$ Assistant Professor, ENT, Head \& Neck Surgery, Khyber Medical College, Peshawar \\ ${ }^{2}$ Clinical Fellow, Neurosurgery, Addenbrooke's Hospital Cambridge, UK \\ ${ }^{3}$ Senior Registrar, ENT, HITEC/ IMS \\ ${ }^{4}$ Core Medical Trainee, Northern Lincolnshire, UK
}

\begin{abstract}
A BST RACT
Background: Cerebrospinal fluid circulates around the surface of brain and spinal cord and through the brain's ventricles. CSF leak is a condition that occurs when the CSF leaks through a defect in the dura or skull and out through the ear or nose. The most common causes of CSF leak include head injury, brain and sinus surgery. The objective of this study was to determine the frequencies of post-traumatic cerebrospinal fluid leak in traumatic head injury.

Material and Methods: A descriptive case series was carried out in the Department of Neurosurgery, Hayatabad Medical Complex,

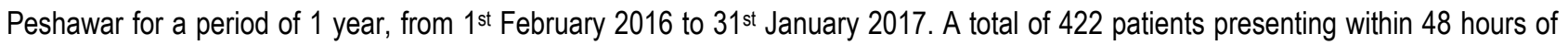
acute trauma to the head were included in a consecutive manner and followed up till $7^{\text {th }}$ day to determine the CSF leak.

Results: The mean age group of our sample was $37.37 \pm 12.3$ years of which $79.6 \%$ were male patients and $20.4 \%$ female patients. Most of the patients (55.5\%) were $\leq 40$ years of age. CSF leak was observed in $5.2 \%$ of patients, with otorrhea seen in $2.1 \%$ patients and rhinorrhea in $3.1 \%$ patients, respectively.

Conclusion: CSF leak is quite common in our population after acute trauma to the head. The high prevalence may be due to high frequency of accidents in our society with high velocity impact and more commonly seen in the younger age group ( $\leq 40$ years).

Key words: Craniocerebral trauma, CSF leak, Otorrhea, Rhinorrhea, Traumatic head injury

Authors' Contribution:

1,2 Conception, synthesis, planning of

research and manuscript writing

Interpretation, discussion, ${ }^{3}$ Active

participations in data collection

${ }^{4}$ Data analysis.

Cite this article. Junaid M, Nabi A, Khan MA, Umair M. Prevalence of Cerebrospinal Fluid

Leak in Traumatic Head Injury at a Tertiary Care Center. J Islamabad Med Dental Coll.2019;

8(3):123-126. doi: 10.35787/jimdc.v8i3.416

\section{Introduction}

Traumatic brain injury is the fourth largest cause of fatal trauma worldwide. ${ }^{1}$ The social and economic implications of traumatic brain injuries are immense whilst the physical and mental bearing upon the patient are devastating. Injury to the head results in a wide spectrum of anatomic and physiologic disruptions which frequently needs expert neurosurgical care. ${ }^{1}$ Trauma to the head might result in leakage of cerebrospinal fluid (CSF) through dural tears in the skull base and at other fracture sites. The reported incidence of post-traumatic CSF leaks is $2 \%$ among the head trauma patients. ${ }^{2}$ These leaks are frequently

associated with basilar skull fractures and present as rhinorrhea, otorrhea and in rare cases as occulorrhoea. ${ }^{1,2}$

The CSF leak may be acute, chronic, spontaneous, iatrogenic, infection/inflammation and tumor associated. Acute or early CSF leaks present within 24 to 48 hours of trauma while the chronic or late leaks present in a delayed fashion such as weeks, months or years later. ${ }^{3}$ Most of the cases of traumatic CSF leaks resolve spontaneously with simple conservative measures such as reclined bed position, blood pressure control, diuretics
\end{abstract}


and does not require repair of the dural and cranial defect. ${ }^{4}$ Current guideline advises conservative treatment of posttraumatic CSF leaks for 10 to 14 days. If the leak does not respond to conservative measures in two weeks, then it is imperative to intervene invasively. . $^{5-7}$

The common investigations performed to detect skull fracture and hence the suspected dural tear area by the high-resolution CT scan is seen with coronal and sagittal cuts. MRI with T2 weighted images in prone position is also highly favored. Radionuclide cisternography, metrizamide contrast test and intrathecal fluorescein dye test are other tests to confirm CSF leaks. Beta transferrin of the leaking fluid and its glucose levels are also helpful in differentiation between CSF rhinorrhea from other causes. ${ }^{7-9}$ Complications of posttraumatic CSF leaks include acute fulminant meningitis with a considerably higher mortality rate, repeated pneumocephalus with the possibility of tension pneumocephalus. ${ }^{9-12}$ Bell et al ${ }^{13}$ has conducted a review of posttraumatic CSF leaks and its management and has reported that these leaks are present in $4.6 \%$ of head trauma patients. However, the true prevalence is unknown because the CSF leaks may appear years after initial dural tear. Sometimes, patients may present with sudden onset acute meningitis which may appear months or years after the initial head injury. ${ }^{13}$

The rationale of this study was to observe frequency of early posttraumatic CSF leaks at our institute. Wide discrepancies exist in the observed frequencies of post traumatic CSF leaks in different studies. By determining the frequencies of post-traumatic cerebrospinal fluid leak in traumatic head injury at our institution, the present study will be helpful to overcome that difference in the observed studies. Furthermore, recording the associated morbidity will help us in delineating the management strategies according to our local expertise and availability of treatment options

\section{Material and Methods}

This study was conducted at Neurotrauma ward, Hayatabad Medical Complex Peshawar. Duration of the study was one year, from $1^{\text {st }}$ February 2016 to $31^{\text {st }}$ January 2017. The study design was descriptive case series in which non-probability consecutive technique was used for sample collection. Patients presenting within 48 hours after the initial head trauma, both male and female, with age ranging from 18 to 65 years were included, while patients who developed post-operative cerebrospinal fluid leaks, those who presented with spontaneous cerebrospinal fluid rhinorrhea or otorrhea or those who developed inflammatory type of cerebrospinal fluid discharge were excluded. Patients were divided into four different age groups ( $\leq 30$ years, 31-40 years, 41-50 years and $\geq 51$ years). All patients meeting inclusion criteria were included in the study through emergency and OPD. Detailed history, clinical examination and diagnosis was confirmed using high resolution CT and MRI of brain, skull base, temporal region followed by routine investigations. Patients were followed during their course of admission till the day of discharge and were assessed for the presence or resolution of the CSF leak. Post stratification was done through chi square test and pvalue less than or equal to 0.05 was considered significant.

\section{Results}

The study was conducted on 422 patients presenting after acute trauma. The mean age of the sample was $37.4 \pm$ 12.4 years (Table I). There were $79.6 \%$ male patients and $20.4 \%$ female patients (Table I). CSF leak was observed in $5.2 \%$ of patients (Table II). Looking at the type of outlet of CSF leak, we observed that $2.1 \%$ of patients had Otorrhea, while $3.1 \%$ patients had Rhinorrhea (Table II). We stratified the CSF leak with regards to different age groups and observed that the difference was statistically significant with a $p$ value of 0.000 . (Table III). CSF leak was also stratified with regards to gender however the difference was statistically insignificant $(p=0.793)$ (Table IV).

\begin{tabular}{|c|c|c|}
\hline Age (years) & Frequency(n) & Percentage (\%) \\
\hline$\leq 30$ & 150 & 35.5 \\
\hline 31 to 40 & 84 & 19.9 \\
\hline 41 to 50 & 104 & 24.6 \\
\hline$\geq 51$ & 84 & 19.9 \\
\hline Total & 422 & \\
\hline Mean \pm SD & \multicolumn{2}{|c|}{$37.4 \pm 12.4$} \\
\hline
\end{tabular}




\begin{tabular}{|l|c|c|}
\hline \multicolumn{3}{|c|}{ Table Il: Frequency distribution of types of CSF leak $\mathbf{( n = 4 2 2 )}$} \\
\hline Type of CSF leak & $\begin{array}{c}\text { Frequency } \\
\mathbf{n}\end{array}$ & $\begin{array}{c}\text { Percentage } \\
\%\end{array}$ \\
\hline Otorrhea & 09 & 2.1 \\
\hline Rhinorrhea & 13 & 3.1 \\
\hline Total CSF leaks & 22 & 5.2 \\
\hline
\end{tabular}

\begin{tabular}{|c|c|c|c|c|}
\hline \multicolumn{5}{|c|}{$\begin{array}{l}\text { Table III: Age wise stratification of patients with CSF leal } \\
\qquad(n=422)\end{array}$} \\
\hline & & \multicolumn{2}{|c|}{ CSF Leak } & \multirow[t]{2}{*}{ Total } \\
\hline & & $\begin{array}{c}\text { Yes } \\
\mathrm{n}(\%)\end{array}$ & $\begin{array}{c}\text { No } \\
\mathrm{n}(\%)\end{array}$ & \\
\hline \multirow{4}{*}{$\begin{array}{l}\text { Age } \\
\text { Groups }\end{array}$} & $\leq 30$ & $7(4.7)$ & $143(95.3)$ & 150 \\
\hline & 31 to 40 & $13(15.5)$ & $71(84.5)$ & 84 \\
\hline & 41 to 50 & $1(1.0)$ & $103(99.0)$ & 104 \\
\hline & $\geq 51$ & $1(1.2)$ & $83(98.8)$ & 84 \\
\hline \multicolumn{2}{|c|}{ Total } & $22(5.2)$ & $400(94.8)$ & 422 \\
\hline \multicolumn{2}{|c|}{$P$ value } & \multicolumn{3}{|c|}{0.0001} \\
\hline
\end{tabular}

\begin{tabular}{|c|c|c|c|}
\hline \multicolumn{4}{|c|}{$\begin{array}{l}\text { Table IV: Gender wise stratification of patients with CSF leak } \\
\qquad(\mathrm{n}=422)\end{array}$} \\
\hline \multirow[t]{2}{*}{ Gender } & \multicolumn{3}{|c|}{ CSF Leak } \\
\hline & $\begin{array}{l}\text { Yes } \\
\mathrm{n}(\%)\end{array}$ & $\begin{array}{c}\text { No } \\
n(\%)\end{array}$ & Total \\
\hline Male $(79.6 \%)$ & $18(5.4)$ & $318(94.6)$ & 336 \\
\hline Female (20.4\%) & $4(4.7)$ & $82(95.3)$ & 86 \\
\hline Total & $22(5.2)$ & $400(94.8)$ & 422 \\
\hline$P$ value & \multicolumn{3}{|c|}{0.793} \\
\hline
\end{tabular}

\section{Discussion}

Nonsurgical trauma accounts for approximately $80 \%$ of CSF leaks. This is in sharp contrast to $16 \%$ of CSF leaks seen after surgical procedures and $4 \%$ due to nontraumatic causes. Of the traumatic leaks, more than $50 \%$ are evident within the first two days of trauma, $70 \%$ within the first week, and almost all present within three months. ${ }^{14}$ CSF traumatic leaks occur commonly in young males and complicate $2 \%$ of all head injuries, and $12 \%$ to $30 \%$ of all basilar skull fractures. ${ }^{11}$ Adoga and colleagues ${ }^{15}$, in their study on otorhinolaryngological manifestations in head trauma found that majority of patients with head injury were male patients and the most affected population was below 40 years. ${ }^{15}$ We report comparable results, as in our study also, most of the patients with head trauma (79.6\%) and CSF leak (82\%; 18/22) were male. Similarly, majority of the patients $(54.4 \%)$ were below 40 years of age.
The common sites of CSF rhinorrhea in cases of accidental trauma are the frontal sinus $(30 \%)$, sphenoid sinus (30\%) and cribriform/ ethmoid (23\%). ${ }^{16}$ Identifying the site of lesion in cases of CSF leak is important and that can be done either through high resolution CT (HRCT) scan or a cisternogram. Localization of lesion is essential for appropriate management plan especially in cases of surgical intervention. ${ }^{11}$ Ji-Woong et all ${ }^{17}$ mentioned in his research article that for diagnosis, laboratory tests and radiological workup is mandatory, as physical examination is not reliable. Furthermore, they added that radiologic findings are important in identification of leaking point and further decision making for management. The radiologic investigations may include plain radiograph of skull bones, high resolution computed tomography (HRCT), CT cisternography, and magnetic resonance imaging (MRI) with intrathecal contrast or cisternography. Similarly, in a study by Oakley ${ }^{18}$ and his colleagues, HRCT is recommended as the first-line study for localization of CSF leak while MR cisternography should be used for CSF leak identification as a second line for each of these if beta- 2 transferrin is not available or if HRCT is not clear. ${ }^{18}$ In our study, we also used these modalities to locate CSF leakage site i.e. $\mathrm{HRCT}, \mathrm{CT} / \mathrm{MRI}$ cisternogram. CSF leaks will usually resolve without surgical intervention in cases of trauma. In refractory cases, successful management often involves a combination of observation, CSF diversion, and/ or extracranial and intracranial procedures. ${ }^{13}$

Unilateral watery nasal discharge is the most common presenting symptom in skull base trauma cases. ${ }^{10}$ Adoga et al, in a study found that common otorhinolaryngological presentations of CSF leaks were rhinorrhea followed by otorrhea. ${ }^{15}$ Contrary to this, Yellinek and his colleagues in their study reported that otorrhea is more frequent then rhinorrhea in cases of CSF leak secondary to traumatic brain injury. ${ }^{19}$ In our study, 22 patients had CSF leaks out of total 422 patients i.e. $5.2 \%$ patients were diagnosed with CSF leak, out of which $2.1 \%$ had CSF otorrhea and $3.1 \%$ had rhinorrhea. Anatomical differences in the skull base bone and dural structures seems to be the reason for above discrepancy. Rhinorrhea is mostly associated with leaning forward or standing. Other nasal conditions, like allergic rhinitis, perennial rhinitis and vasomotor rhinitis, are common, and may mimic the signs and 
symptoms of CSF rhinorrhea or may occur simultaneously with a CSF leak. If test is performed during the quiescent phase, there are chances of false-negative results on diagnostic testing. Repeat testing and further follow-up is required in cases of high clinical suspicion. 10,13

\section{Conclusion}

CSF leak is common in our population after traumatic head injury. The high prevalence may be due to high number of accidents in our society with high velocity impact and more commonly seen in the age group less than 40 years.

\section{References}

1. Algattas $\mathrm{H}$, Huang JH. Traumatic Brain Injury Pathophysiology and Treatments: Early, Intermediate, and Late Phases Post-Injury. Int. J. Mol. Sci. 2014; 15(1): 309-41. Doi: 10.3390/ijms15010309

2. Gray S.T, Wu A.W. Pathophysiology of latrogenic and Traumatic Skull Base Injury. Adv Otorhinolaryngol. 2013; 74: 12-23. Doi: 10.1159/000342264

3. Posser JD, Vender JR, Solares CA. Traumatic cerebrospinal fluid leaks. Otolaryngol Clin N Am. 2011; 44(4): 857-73. Doi: 10.1016/j.otc.2011.06.007

4. Schoentgen C, Henaux PL, Godey B. Management of post-traumatic cerebrospinal fluid (CSF) leak of anterior skull base: 10 years' experience. Acta Otolaryngol. 2013; 133(9): 944-50. Doi: 10.3109/00016489.2013.793821

5. Kumar BR, Sahu R, Srivastava AK, Nair AP, Mehrotra A. Surgically repaired posttraumatic CSF rhinorrhea: An institutional experience and review of literature. Indian J Neurosurg 2012; 1(1): 23-7. Doi: 10.4103/2277-9167.94366

6. Kim SW, Park HW, Jeon SY. Versatility of the pedicled nasoseptal flap in the complicated basal skull fractures. Auris Nasus Larynx. 2013; 40(3): 3347. Doi: 10.1016/j.anl.2012.07.013

7. Tahir MZ, Khan MB, Bashir MU, Akhtar S, Bari E. Cerebrospinal fluid rhinorrhea: $A n$ institutional perspective from Pakistan. Surg Neurol Int. 2011; 2: 174. Doi: 10.4103/2152-7806.90689

8. Pease M, Marquez $\mathrm{Y}$, Tuchman A. Diagnosis and surgical management of traumatic cerebrospinal fluid oculorrhea: case report and systematic review of the literature. J Neurol Surg Rep. 2013; 74(1): 57-66. Doi: 10.1055/s-0033-1347902

9. Aurangzeb A, Ahmed E, Khan SA. Outcome of transcranial repair of traumatic CSF rhinorrhoea. $J$ Ayub Med Coll Abbottabad. 2012; 24(2): 47-9. PMID: 24397051

10. Bhatti SN, Khan SA, Shah R. Transnasal endoscopic repair of cerebrospinal fluid rhinorrhoea. J Ayub Med Coll Abbottabad. 2011; 23(2): 15-7. PMID: 24800333

11. Luszczyk MJ, Blaisdell GY, Wiater BP. Traumatic dural tears: what do we know and are they a problem? Spine J. 2014; 14(1): 49-56. Doi: 10.1016/j.spinee.2013.03.049

12. Chaudhary N, Awan LM, Niaz A. Success determination of lumber drainage in cranial traumatic CSF fistula. J Spine Neurosurg. 2013; 2(5). Doi: 10.4172/2325-9701.1000121

13. Bell RB, Dierks EJ, Homer L, Potter BE. Management of cerebrospinal fluid leak associated with craniomaxillofacial trauma. J Oral Maxillofac Surg. 2004; 62(6): 676-84. Doi: 10.1016/j.joms.2003.08.032

14. Kerman $M$, Cirak B, Dagtekin A. Management of skull base fractures. Neurosurg Q. 2002; 12(1): 23-41.

15. Adoga AA, Ozoilo KN, Iduh AA, Mugu JG. Otorhinolaryngological manifestations in head trauma: A prospective study of the epidemiology, clinical presentations, management, and outcomes. Int J Crit Illn Inj Sci. 2017; 7(4): 231-35. Doi: 10.4103/IJCIIS.IJCIIS_108_16

16. Banks CA, Palmer JN, Chiu AG, et al. Endoscopic closure of CSF rhinorrhea: 193 cases over 21 years. Otolaryngol Head Neck Surg. 2009; 140(6): 826-33. Doi: 10.1016/j.otohns.2008.12.060

17. Oh JW, Kim SH, Whang K. Traumatic Cerebrospinal Fluid Leak: Diagnosis and Management. Korean $\mathrm{J}$ Neurotrauma. 2017; 13(2): 63-67. Doi: 10.13004/kjnt.2017.13.2.63

18. Oakley GM, Alt JA, Schlosser RJ, Harvey RJ, Orlandi RR. Diagnosis of cerebrospinal fluid rhinorrhea: an evidence-based review with recommendations. Int Forum Allergy Rhinol. 2016; 6(1): 8-16. Doi: 10.1002/alr.21637

19. Yellinek S, Cohen A, Merkin V, Shelef I, Benifla M. Clinical significance of skull base fracture in patients after traumatic brain injury. J Clin Neurosci. 2016; 25: 111-5. Doi: 10.1016/j.jocn.2015.10.012. 